\title{
INFLUENCE OF MECHANICAL DISTURBANCE ON OCULOMOTOR BEHAVIOR
}

\author{
Uwe J. Ilg, ${ }^{1 *}$ Bruce Bridgeman ${ }^{2}$ and Klaus P. HoffmanN ${ }^{1}$ \\ 'Universitaet Ulm, Abteilung Vergl. Neurobiologie, 7900 Ulm. Postfach 4066, F.R.G. and 'Program in \\ Experimental Psychology, University of California, Santa Cruz, CA 95064, U.S.A.
}

(Received 9 July 1987; in final revised form 7 October 1988)

\begin{abstract}
Using a binocular search coil technique, we measured oculomotor behavior during gentle pressing with a finger on the outer canthus of one eye. With a steadily pressed viewing eye, and the fellow eye occluded, the occluded eye deviates while the pressed eye does not. If the eye is rapidly pressed and released, the compensation of rotational force in the pressed eye becomes incomplete, so that both eyes move. At high frequencies of press ( $>1 \mathrm{~Hz}$ ) the pressed eye is deviated and the contralateral eye no longer moves. In darkness the pressed eye always rotates but the contralateral eye never does, demonstrating that any inflow from proprioceptors sensing rotation of the pressed eye does not affect oculomotor posture as measured in the fellow eye. With binocular viewing the results are more variable. On some trials neither eye moves, while on others both move. The results can be interpreted as a Hering's law controlled attempting to reconcile disparate inputs from the two eyes. The results confirm and extend, with objective measures, earlier conclusions from subjective experiments.
\end{abstract}

\section{INTRODUCTION}

Space perception and visually guided behavior require information about the locations of objects in space. This information is obtained by combining the locus of an object's projection on the retina with information about the location of the eyes in the head. A change in the algebraic sum of these variables indicates object motion.

To determine how interactions of gaze position and oculomotor innervation contribute to the task of analyzing motion and position, we measured oculomotor behavior under conditions where the relationship between gaze position and innervation state was mechanically altered. Our method is a press with the finger on the outer canthus of the eye, a technique which has undergone development in the past few years (Stark \& Bridgeman, 1983; Bridgeman \& Fishman, 1985).

All of the work using the eye-press method to date has used a monocular measure, with only the pressed eye exposed and only the occluded eye monitored. Further, earlier experiments were restricted for the most part to static conditions of viewing. We report here on an extension of the method to binocular stimulation and recording, using a precise 2-dimensional recording method. We also extend the observations to

*Reprint requests should be addressed to: Uwe J. Ilg, Allg. Zoologie und Neurobiologie, D-4630 Bochum, Postfach 1021 48, F.R.G. dynamic behavior of the eyes. Previous psychophysical experiments (Bridgeman \& Stark, 1981; Bridgeman \& Delgado, 1984; and those cited above) using subjective measures to validate the eye-press method are supplemented here with objective eye monitoring.

\section{METHOD}

\section{Apparatus}

Figure 1 shows the experimental apparatus. The positions of both eyes were measured by using two scleral search coils (Skalar medical). We used the technique developed by Robinson (1963) and adapted for human use by Collewijn, van der Mark and Jansen (1975). Helmholtz coils generated two alternating magnetic fields (17.5 and $35 \mathrm{kHz}$ ), and four lock-in amplifiers measured the amplitudes of the voltages induced in the search coils. The coils were imbedded in silicone rings which adhere to the sclera, omitting the locally anesthetized cornea. The method offers absolute calibration in space without distortion of the records by lateral displacements of the eye due to eye-press. It was possible to record from an eye and exert pressure simultaneously. The head of a subject was fixed in the homogeneous center of the fields with forehead and chin rests; the small displacements of the eye resulting from eye pressure (less than $1 \mathrm{~cm}$, toward the contralateral eye) did not displace the eye from the region of uniform 
Experimental setup

two homogeneous

alternating

magnetic fielos

computer

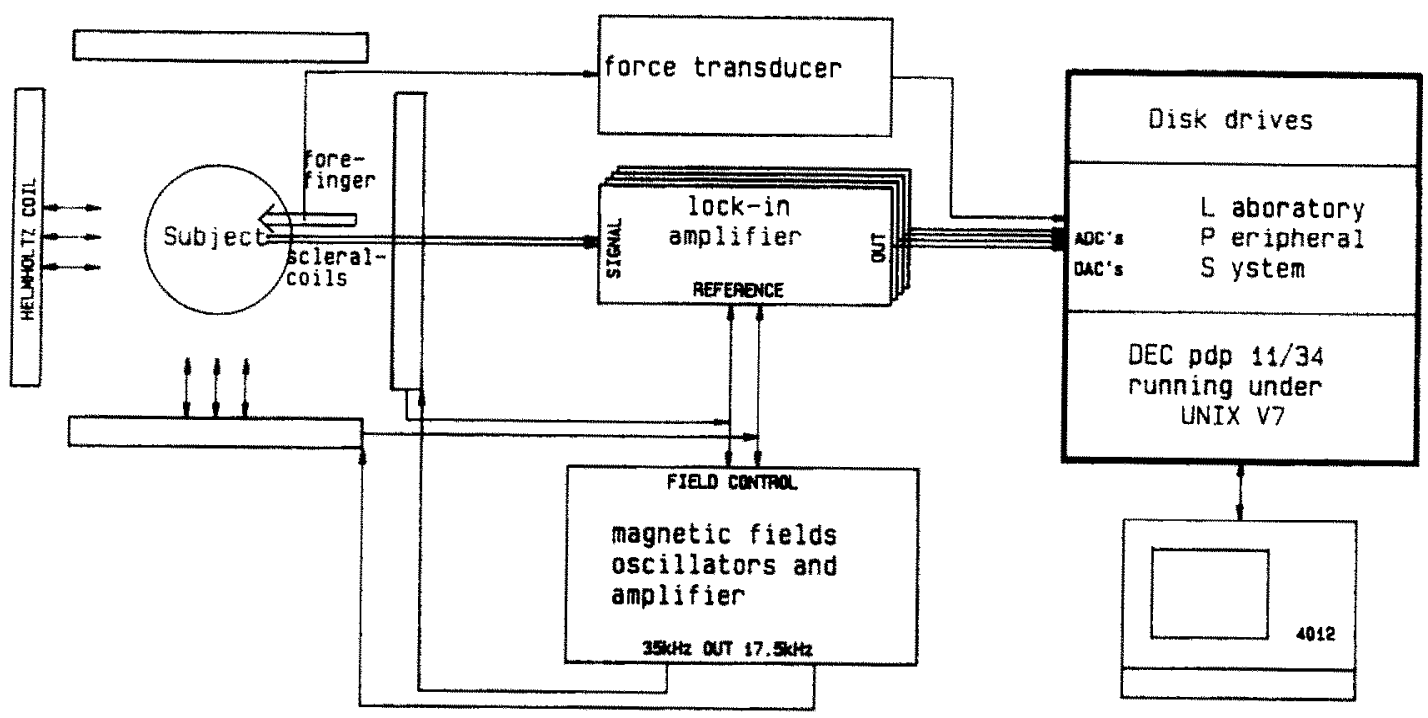

Fig. 1. Experimental apparatus for eye-press experiments.

magnetic fields where calibration is independent of coil translatory movements. The lack of recorded rotation of the eye with a gradual eye-press demonstrated the lack of distortion of recorded eye position with eye-press.

The subject exerted pressure on the eye with his own forefinger. Pressure on the right eye (always the right eye) was measured with a force-resistance transducer (BLH semiconductors) connected to the finger by a flexible but nonelastic cord. By comparing the eye position with the finger position we could obtain continuous objective records of the relationship between the eye-press and the oculomotor response. Output signals of the lock-in amplifiers (eye position) and the force transducer (finger position) were sampled by a four channel $A / D$ converter (DEC LPS) at a sampling rate of $200 \mathrm{~Hz}$ in each channel. Because the sampling was the limiting factor in the recording system, the effective bandwith of the system was $100 \mathrm{~Hz}$. The sensitivity of the search coil was about $0.525 \mathrm{~V} / \mathrm{deg}$ depending on subject and individual coil.

Finger position was estimated by the force applied to the eye and monitored at the transducer; the relation between force and position introduced quantitative nonlinearities, so that the output from the transducer was useful mainly to assess the actual temporal frequency of the eye-press, and its regularity, with an objective method. Phase delays in the transducer recording were minor at the relatively low temporal frequencies $(<4 \mathrm{~Hz})$ used here.

The visual stimulus was a random-dot pattern (one pixel $=1.5$ degree of visual angle) subtending a field of $90 \times 90 \mathrm{deg}$. The pattern was back projected from a slide whose movement was controlled via servomotors. In some trials these servomotors were controlled by the output of the lock-in amplifier and could move the slide in $x$ and $y$ directions to stabilize the image relative to the position of either search coil. Viewing distance was $60 \mathrm{~cm}$.

\section{Procedure}

Three conditions of visual stimulation were examined: monocular, binocular, and darkness. In the monocular condition, the left eye (without pressure) was covered with an opaque black hemisphere (dia. $4.5 \mathrm{~cm}$ ) which allowed the covered eye to move freely. In the binocular and darkness conditions, both eyes were open and recorded.

In all conditions the corneas were anesthetized with a local anesthetic before the coils were applied. Experimental sessions were limited to about $30 \mathrm{~min}$. There were two subjects (female and male), both experienced psychophysical observers who had experience with the search coil technique but had not participated in eyepress experiments previously. Neither subject 
had any clinically manifest phorias or other abnormalities of binocular vision. One subject had corrected vision (7.5 D, near-sighted).

To acquire the presented data, we collected eye and finger position for $31 \mathrm{sec}$ for each data file. The results presented here are based on 64 such datafiles. For documentation we were able to plot eye and finger position in an adjustable interval. The eye-press-related eye movements were analyzed off-line.

\section{RESULTS}

Typical observed eye-movements are described as follows.

\section{Monocular condition}

Figure 2 shows eye movements recorded in the monocular condition for subject GSt. With a low temporal frequency of eye-press, the pressed (right) eye remains stable while the occluded (left) eye oscillates with the same frequency as the force transducer. Lack of rotation of the pressed eye demonstrates that calibration of the coil is maintained during an eye-press; it would require remarkable coincidence if the coil slippage exactly matched the frequency and phase of eye rotation through the record of Fig. 2.

Lack of significant rotation of the pressed eye indicates that the ipsilateral lateral rectus muscle pulls the eye to the right with the same force as the forefinger pressing the eye to the left.
Table 1. Frequency dependence of amplitudes of movements of both eyes caused by eye-press on the right eye. Indicated are the number of trials $(n)$ and the mean amplitude and standard deviation (SD) of eye movements

\begin{tabular}{|c|c|c|c|c|c|}
\hline \multirow[b]{2}{*}{$\begin{array}{l}\text { Frequency } \\
(\mathrm{Hz})\end{array}$} & \multirow[b]{2}{*}{$n$} & \multicolumn{2}{|c|}{ Right eye } & \multicolumn{2}{|c|}{ Left eye } \\
\hline & & Mean & SD & $\begin{array}{l}\text { Mean } \\
\quad \text { (deg) }\end{array}$ & SD \\
\hline 4.0 & 27 & 1.55 & 0.30 & 0 & 0 \\
\hline 3.1 & 53 & 1.90 & 0.51 & 0 & 0 \\
\hline 2.0 & 26 & 1.45 & 0.58 & 0 & 0 \\
\hline 0.98 & 25 & 1.90 & 0.57 & 1.65 & 0.33 \\
\hline 0.92 & 23 & 1.29 & 0.41 & 1.48 & 0.77 \\
\hline 0.82 & 21 & 1.40 & 0.27 & 1.33 & 0.45 \\
\hline 0.73 & 19 & 1.66 & 0.52 & 1.70 & 0.58 \\
\hline 0.4 & 18 & 0 & 0 & 2.33 & 0.98 \\
\hline
\end{tabular}

Under static conditions, when the right eye was pressed the left eye of subject KPH rotated $3.4 \mathrm{deg}(n=7, \mathrm{SD}=1.62 \mathrm{deg})$. The left eye of subject GSt rotated $2.3 \mathrm{deg}(n=18$, $\mathrm{SD}=0.98 \mathrm{deg}$ ) under the same condition.

Table 1 shows the frequency dependence of the movements elicited by eye pressure for subject GSt. For the lowest frequency of eye-press, the occluded eye oscillated while the pressed eye did not. At intermediate frequencies both eyes moved, and at highest frequencies $(<1 \mathrm{~Hz})$ the pressed eye oscillated while the occluded eye was unresponsive.

\section{Darkness}

Figure 3 shows that in darkness the pressed eye of subject KPH slowly shifts to the left, with eye-press-induced oscillations superimposed. Without visual feedback the pressed eye is not

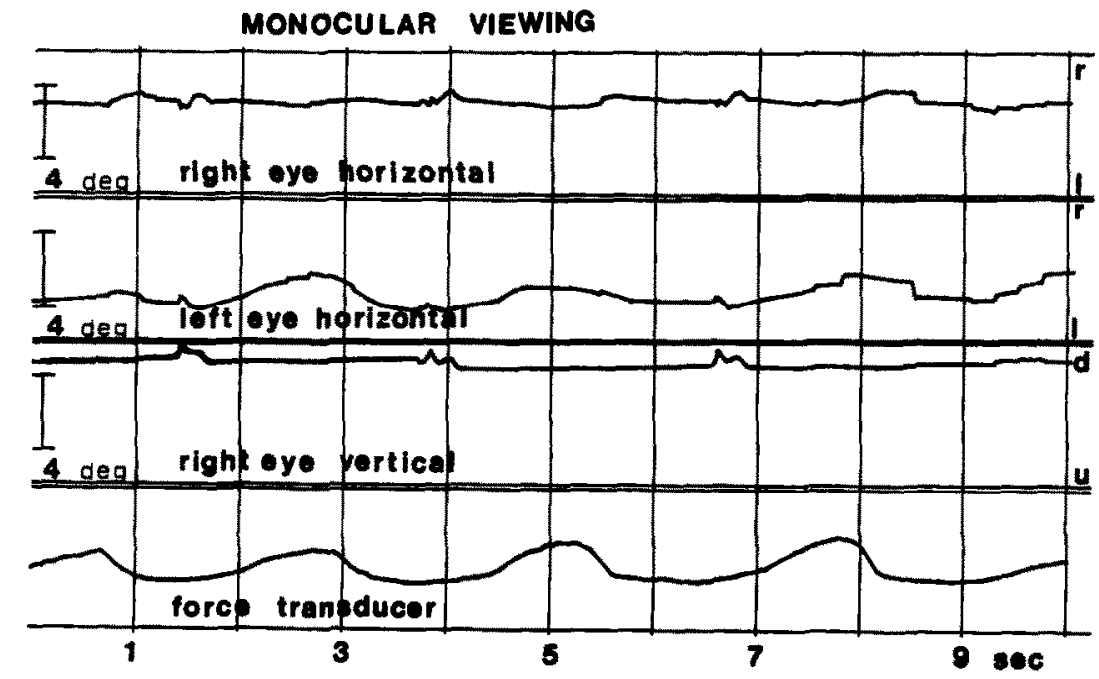

Fig. 2. Eye movements in the monocular condition (right eye pressed, left eye covered) of the subject GSt. Each trace represents eye position or finger position as indicated. Time is plotted on the abscissa (in seconds); r: right, l: left; u: up; d: down. 


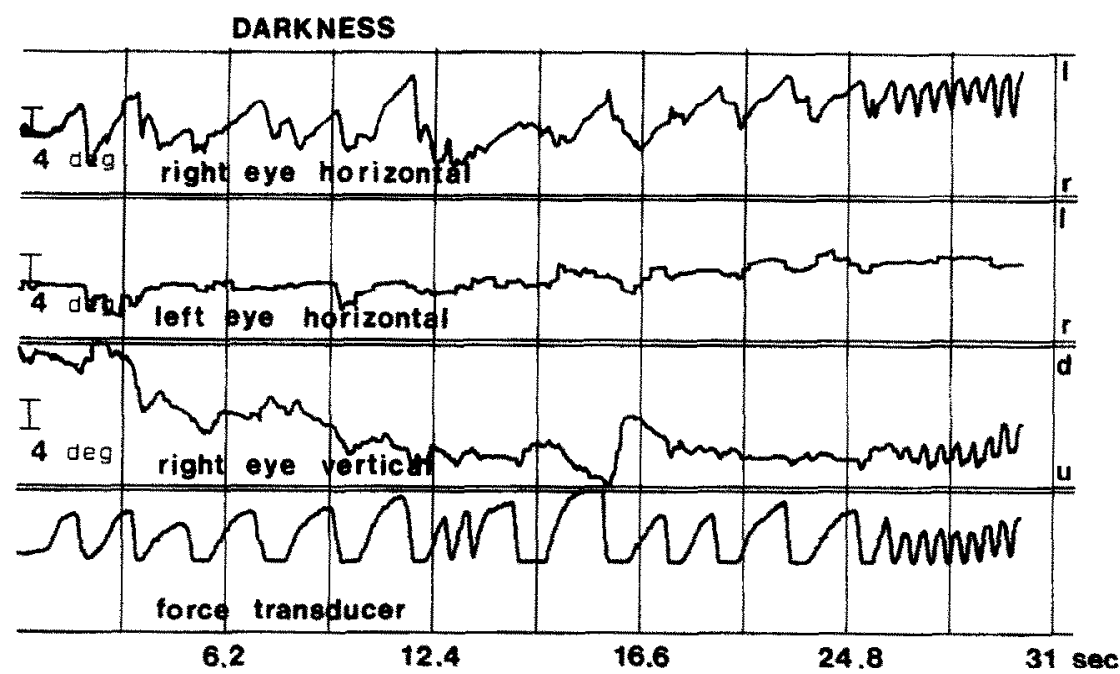

Fig. 3. Eye movements in darkness of the subject KPH. For explanation see Fig. 2. The time scale is compressed relative to Fig. 2; the frequency of eye-press is about the same in both figures.

stabilized, and the opposite eye is unaffected. Since the pressed eye is shown to rotate in the orbit, any proprioceptors that respond to eye rotation should be stimulated. They do not, however, have any reflex connections to affect the posture of the contralateral eye.

\section{Binocular}

With binocular stimulation the experimentally induced eye movements are somewhat more variable than they were under the other two conditions. Subjects were instructed to fixate a point at the center of the tangent screen while pressing on the eye. Figures 4 and 5 show the pattern of movement most common in two subjects. In Fig. 4, both eyes fail to show any movements at all.

Figure 5 shows a qualitatively different pattern. In this example the right eye yields to the exerted pressure and turns to the left. Concurrently, the opposite (left) eye rotates to the right, increasing the angle of convergence. When the pressure on the right eye is relieved, both eyes diverge. The subjects generally experienced diplopia under these conditions.

There was also a frequency dependence here, as Fig. 5 shows: gradual changes in pressure on the eye were cancelled in both eyes, presumably by compensatory version and vergence inner-

\section{BINOCULAR VIEWING}

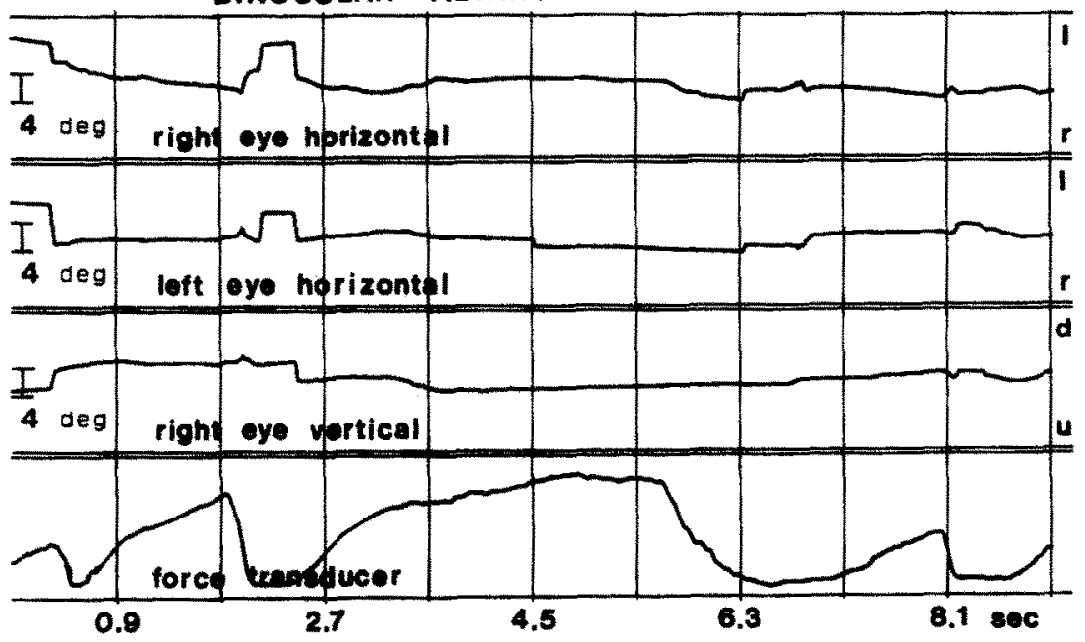

Fig. 4. Lack of correlated eye movements in the binocular condition of the subject KPH. For explanation see Fig. 2. 
BINOCULAR VIEWING

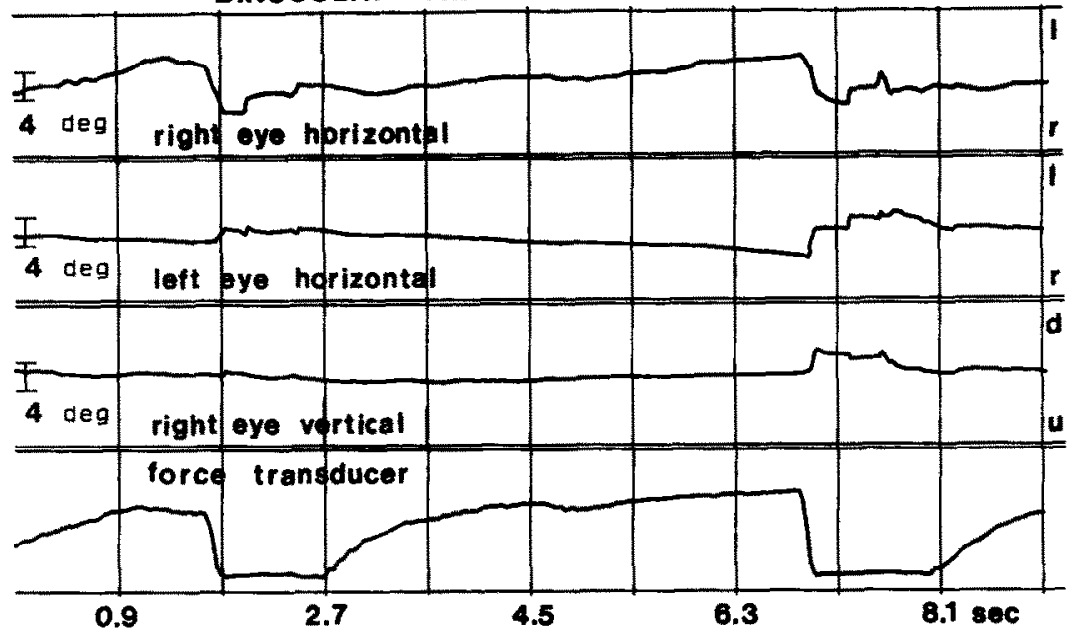

Fig. 5. Stimulus-related eye movements in the binocular condition of subject KPH. For explanation see

Fig. 2.

vation, while rapid changes of the same magnitude resulted in binocular vergence motions.

\section{DISCUSSION}

Our results can be interpreted in terms of an analysis of the eye-press developed by Stark and Bridgeman (1983) and Bridgeman (1983). The classical analysis (Decartes, 1972; Helmholtz, 1867), that finger pressure on a monocularly viewing eye causes passive eye movement and motion of the visual world on the retina, does not apply to static or slowly changing pressure. At low temporal frequencies, the oculomotor system compensates for the first sign of angular deviation of the eye by an active compensatory innervation. As a result, the eye being pressured tracks the visual target and remains fixated on it despite the press. As our results show, the image does not move appreciably on the retina; instead, the extraocular muscles resist the attempted rotation more and more as the finger pressure becomes greater and greater. The resulting apparent motion is a result of the innervation state influencing perception, since the retinal image does not move (Bridgeman, 1979).

The present data verify with objective eye movement records the lack of movement of the pressed eye. This confirms the conclusion of Stark and Bridgeman (1983) from an indirect method: a difficult color discrimination in a small target, possible only in foveal vision, could be performed even during the dynamic phase of eyepress (while subjects experienced apparent motion). Thus, we knew that the fovea continued to fixate the target even during apparent motion.

Further psychophysical experiments by Stark and Bridgeman (1983) analyzed the mechanical and perceptual events during monocular eyepress. A parallax method showed that an eyepress displaces the eye medially in the orbit as a result of combined pressure from the finger and the lateral rectus muscle. A structured visual field reduces the perceptual effects of changed oculomotor efference (Matin et al., 1982). A pointing measure, however, shows effects of changed efference both with and without a structured visual field (Stark \& Bridgeman, 1983).

In the present paper, we have shown that the response of the oculomotor system to mechanical deviation of one eye depends upon the rate of eyepress and on the stimulus conditions. Because the eye is normally engaged in fixation or smooth (low-frequency) pursuit, the following discussion emphasizes the steady-state case.

\section{Monocular}

Using two scleral search coils we found that with a slow rate of eyepress and monocular viewing, only the occluded eye deviates. Table 2 , line 1 shows this result - the first column shows the response of the pressed eye, while the second column shows the simultaneous reaction of the eye contralateral to the press. The increased oculomotor effort required to prevent the viewing eye from rotating results in a secondary deviation of the covered eye. 
Table 2. Oculomotor effects of steady-state eye-press on the pressed eye and the normal (contralateral) eye

\begin{tabular}{lcc}
\hline & \multicolumn{2}{c}{ Eye motion } \\
Stimulus & Pressed & Normal \\
\hline Monocular & - & + \\
Dark & + & - \\
Binocular & - & - \\
& $(+)$ & $(+)$ \\
\hline
\end{tabular}

This effect has a very long time constant. For pressure frequency larger than $0.98 \mathrm{~Hz}$ only the pressed eye moves passively. For frequency in between 0.98 and $0.73 \mathrm{~Hz}$ the covered eye starts to move in a compensatory manner. Only for pressure frequency smaller than $0.73 \mathrm{~Hz}$ the pressed eye is stabilized and only the covered eye shows the innervation. This effect can be interpreted as a phase lag of attempted compensations for the retinal image motion induced by the eye-press.

Hering's law (Hering, 1977) holds true in the monocular condition, since the pattern of movements can be explained by the left medial rectus and the right lateral rectus muscles receiving the same pattern of innervation. The innervations are equal even though the movements are not.

\section{Darkness}

The experiments in darkness (Table 2, line 2) show that only the visual input, and not the proprioceptive input, contributes to ocular stabilization under normal viewing conditions. Our major result is that input from the extraocular muscle proprioceptors has a negligible effect on ocular posture. This result replicates the "darkness" condition of Bridgeman and Delgado (1984), using binocular monitoring with a more precise eye movement monitoring technique. Without a visual image to generate an error signal for tracking, the pressed eye moves passively in the orbit. Under this stimulus condition, the Helmholtz kinematic assumptions for the eye-press are accurate even at low temporal frequencies.

In this study we measured the response of the oculomotor system to a mechanically induced deviation of eye position. This response contains no signal from the proprioceptors in the extraocular muscles.

\section{Binocular}

The results in the binocular condition are more difficult to explain. Hering's law seems to be violated (Bahill et al., 1976) because the pressed eye exerts a rotational force counteracting the pressure, while the free eye maintains its position.

Because the right eye must be innervated for a deviation to the right, while the left eye must maintain its position, the only way to maintain fixation binocular consistent with Hering's law is a combination of a slight pursuit version movement to the right with a divergence. These movements will cancel in the left eye and sum in the right. But divergence of more than a few degrees from parallel position is not possible in normal subjects (Hering, 1977). As long as the magnitude of the eye-press does not exceed the divergence limit, the "Binocular" results in Table 2 is possible. This analysis predicts that subjects should be able to maintain binocular fixation for a stronger eyepress when they are converged on a near target than when they are fixating a distant target, because more divergence from the original fixation position is available.

Evidence that the oculomotor system is not idle under binocular viewing, even though neigher eye is moving, comes from the recordings under open-loop conditions. The signals from the left eye moved the visual stimulus in the same direction and magnitude as the eye movement, so that eye movements did not change the position of the stimulus on the retina. Thus the stimulus was open-loop for the left eye, and closed-loop for the right, pressed eye. In this condition pressing on the eye resulted in stimulus movements, showing that a (normally cancelled) compensatory innervation reaches the contralateral eye.

If the eye-press becomes larger than the subject's divergence limit, stabilization of both eyes becomes impossible and the result given in parentheses in Table 2 is seen. The strong vergence movements seen under this condition may represent the unsuccessful effort of the oculomotor control system to stabilize both eyes.

In our binocular experimental condition with stabilization of the image in the unpressed eye, vergence movements did not result in a perception of movement in depth. This result is consistent with earlier findings (Westheimer \& Mitchell, 1969; Collewijn, Erkelens \& Regan, 1985) with small movements of a binocular target in depth, the direction of vergence was generally accurate even when a forced-choice estimate of direction of movement was not. 


\section{CONCLUSIONS}

We conclude that Hering's law and the operation of negative feedback to stabilize the position of the images on both retinas can account for most of our results. The microstructure of the movements, however, often violates Hering's law transiently. Error signals from each eye separately contribute to corrective eye movements that control the eyes binocularly. The control system that stabilizes eye posture is heavily damped, and operates in a much lower temporal frequency range than either pursuit or saccadic systems. Current evidence favors outflow as the most likely source of oculomotor information that is combined with retinal images to yield perception of position and motion.

\section{REFERENCES}

Bahill, A. T., Ciuffreda, J., Kenyon, R. \& Stark, L. (1976). Dynamic and static violations of Hering's law of equal innervation. American Journal of Optometry and Phys. iological Optlcs, 53, 786-796.

Bridgeman, B. (1979). Adaption and the two-visual hypothesis. Behavioral and Brain Sciences, 2, 84-85.

Bridgeman, B. (1983). Mechanisms of space constancy. In Hein, A. \& Jeannerod, M. (Eds.) Spatially oriented behavior (pp. 263-279). New York: Springer.

Bridgeman, B. \& Deigado, D. (1984). Sensory effects of eyepress are due to efference. Perception and Psycho. physics. 36, 482-484.
Bridgeman, B. \& Fishman, R. (1985). Dissociation of corollary discharge from gaze direction does not induce a straight-ahead shift. Perception and Psychophysics, 37 (6), 523-528.

Bridgeman, B. \& Stark, L. (1981). Efferent copy and visual direction. Investigative Ophthalmology and Visual Science (Suppl.) 20, 55.

Collewijn, H., van der Mark, F. \& Jansen, T. (1975). Precise recording of human eye movements. Vision Research, 15, 447-450.

Collewijn, H., Erkelens, C. F. \& Regan, D. (1985). Absolute and relative disparity: a re-evaluation of their significance in perception and oculomotor control. In Keller, E. L. \& Zee, D. S. (Eds.) Adaptive processes visual and oculomotor systems (pp. 321 -328). Oxford: Pergamon Press.

Decartes, R. (1972). Treatise of man. (Translated and edited by Hall, T. S.). Cambridge, Mass: Harvard University Press (originally published 1664).

Helmholtz, H. von (1867). Handbuch der physiologischen Optik. Leipzig; Voss.

Hering, E. (1977). Bridgeman, B. \& Stark, L. (Eds.) The theory of binocular vision (translated by Bridgeman, B.). New York: Plenum Press (originally published 1868).

Matin, L., Picoult, E., Stevens, J., Edward, M., Young, D. \& MacArthur, R. (1982). Oculoparalytic issusion: Visualfield dependent spatial mislocalizations by humans partially paralyzed with curare. Science, N.Y. 217, 198-201.

Robinson, D. A. (1963). A method of measuring eye movements using a scleral search coil in a magnetic field. IEE Transactions Biomedicine and Electronics BME 10, 137-145.

Stark, L. and Bridgeman, B. (1983). Role of the corollary discharge in space constancy. Perception and Psychophyiser, 34, 371-380.

Westheimer, G. \& Mitchell, D. (1969). The sensory system for disjunctive eye movements. Vision Research. 9, 749-755. 